\title{
CYPRUS 2016: Sustainable Solid Waste Management
}

\author{
Maria Loizidou ${ }^{1}$
}

Published online: 6 July 2017

(c) Springer Science+Business Media B.V. 2017

It is well known that significant quantities of waste materials from various sources could be used in several applications to obtain new products-materials and hence save primary resources. In a time period that environmental awareness becomes more important and technologies are advancing very fast, the promotion of circular economy and the development of symbiotic networks should be enhanced in a large number of different areas. The target is to move towards new products and chemical building blocks of high value derived from the generated waste offering new and viable alternatives at technological level to satisfy the increasing needs of life and economy nowadays.

This section of the Special Issue includes the best papers selected from the Cyprus 2016 4th International Conference on Sustainable Solid Waste Management (http://www. cyprus2016.uest.gr) held in Limassol, Cyprus 23rd-25th June 2016.

Following the Athens 2012, the Athens 2014 and Tinos 2015 International Conferences, the Cyprus 2016 4th International Conference on Sustainable Solid Waste Management aimed to address the significant issues for sustainable solid waste management through the promotion of effective technologies and success practices, stimulating the interest of scientific community, competent authorities, public and private sector on the latest developments in the specific field. The Conference provided an opportunity to bring together scientists and professionals from government departments, municipalities, private institutions, research

Maria Loizidou

mloiz@ chemeng.ntua.gr

1 School of Chemical Engineering, Unit of Environmental Science \& Technology, National Technical University of Athens, 9 Heroon Polytechniou Street, Zographou Campus, 15773 Athens, Greece and education institutions, being a forum for the exchange of the most recent ideas, techniques and experiences in all areas of solid waste management.

Selected high quality papers presented in the Cyprus 2016 Conference are included in this Special Issue of Waste and Biomass Valorization covering various areas, such as tools for waste valorization, waste management systems in remote areas, specific waste stream treatments, advanced bioprocesses to bio products and anaerobic processes.

More specifically, Hemidat et al. deal with key indicators of waste collection using GIS techniques for route optimization. The paper of San Martin et al. is related to decision support tools combining AHP method with GIS for implementing food waste valorisation strategies, while Vakalis et al. handle statistical entropy analysis of heavy metals from combustion of agricultural waste. The paper by Smoliński et al. involves chemometric modelling of experimental data on co-gasification of bituminous coal and biomass to hydrogen-rich gas and the work by Guedes et al. addresses phosphorus recovery in sewage sludge by electrokinetic based technologies.

In the field of waste management systems in remote areas such as islands, the implementation and evaluation of an integrated management scheme for municipal solid waste in selected communities in Tinos Island is discussed by Panaretou et al., while another paper by Mancini et al. focuses on an approach to islands' self-contained waste management system with the goal of maximizing the recovery, while limiting transportation costs.

Management of specific solid waste streams and wastewater by Valta et al. includes review papers, the first on solid waste and wastewater from fruit and vegetable processing industries and the second on cheese whey and wastewater by cheese manufacturing units. The benchmarking of low environmental footprint biological processes for 
the treatment of industrial waste streams is addressed by Massara et al., while Santos et al. address the management options for construction and demolition waste. The work by Jeguirim et al. presents chemometric analysis for the relationship between mineral contents and particle matter distribution during pellets combustion.

Advanced bioprocesses to convert waste to bioproducts are well presented. In this filed calcium rich food wastes based catalysts for biodiesel production by Ramos et al. is included, while the next paper presents evaluation of an innovative pilot system for the conversion of biowaste into bioethanol by Sotiropoulos et al. The isolation of $\beta$-glucans from selected Basidiomycetes strains grown in olive oil mill wastewater is another interesting paper by Zerva et al. The work by Noorul Hussain et al. is related to numerical modelling of sonicated, numerical simulation and experimental testing of novel sonochemical reactor for transesterification.

Anaerobic processes for agricultural waste and production of biogas is covered by two papers. The first one deals with a quantitative and qualitative analysis focused on biogas production by Chávez-Fuentes et al., while Michalopoulos et al. address valorization of the liquid fraction of a mixture of livestock waste and cheese whey for biogas production through high-rate anaerobic co-digestion and for electricity production in a microbial fuel cell.

The eighteen papers included in this section present scientific initiatives and attempts at worldwide level in order to make a step forward in the field of waste management and valorization, either through biological, chemical or thermal processes.

The Conference was organized within the Life + Livewaste project (LIFE12 ENV/CY/000544) (http://www. livewaste.org) dealing with the development, demonstration and evaluation of an innovative decentralized approach for sustainable management of livestock waste achieving environmental protection and climate change mitigation. It is important to note that two more Life + projects, waste2bio (http://www.waste2bio.eu) and Agrostrat (http://www. agrostrat.gr), have contributed to organizing a fruitful conference event.

Concluding, I would like to state that I am grateful to Prof. Ange Nzihou, the Editor-in-Chief of Waste and Biomass Valorization for giving the opportunity to publish selected reviewed papers of high quality in a Special Issue of Waste and Biomass Valorization. 